\title{
تحليل المهارة اللغة العربية في التلاميذ
}

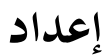 \\ أمي لستنا، علي أسرون لوبيس
}

تجريد

هذه الرسالة عبارة تحت الموضوع تحليل المهارة اللغة العربية في التلاميذ في المدرسة الثانوية الأهلية دار العلوم سيباجوا. المسئلة الأساسية في هذ البحث يعني مشكلات التلاميذ في مهارة اللغة العربية يعني كيف بيئة التعليم اللغة العربية التلاميذ في مدرسة دار العلوم سيباجوا وما هوالصعوبات التي توجهها التلاميذ في مدرسة دار العلوم سيباجوا. وأهداف من هذا البحث هولمعريفة مهارة الكلام باللغة العربية عند التلاميذ في مدرسة دار العلوم سيباجوا.

نتائج هذ البحث أن المهارة على التحدث باللغة العربية هي قادرة على التحدث باللغة العربية، وضرورية للغوية للطلاب في تعلم اللغة العربية. إن استخدام المفردات سوف يسهل ويساعد الطلاب على فهم اللغة شفهية وكتابا. كما هومعروف أن المهارات التي يمتلكها الطلاب في استيعاب الدروس يجب أن يكون لها مهارات مختلفة. موجود أوليك الذين لديهم المهارة على استيعاب الدروس بسرعة، موجود أولئك الذين لديهم مهارات ليست بسرعة الكافية. البيئة مؤثرة للغاية في استمرار التعلم خاصة في دروس اللغة العربية. الصعوبات التي يواجهها التلميذ الطلاقة والطلاقة في التحدث اللغة العربية بالطيب وصحيح. وبتح صعوبة في حفظ المفردات كسولا جدا لقولها ونقص تعلم النحوا وصرف لذلك يصعب التمييز بين فعل. 


\section{الكلمة المفتوحة : المهارة اللغة العربية: تحليل المهارة اللغة العربية في التلاميذ}

\section{المقدمة}

Spradley التحليل هواغهيار أوالتحقيق في حدث لمعرفة الوضع الحقيقي. وفقال

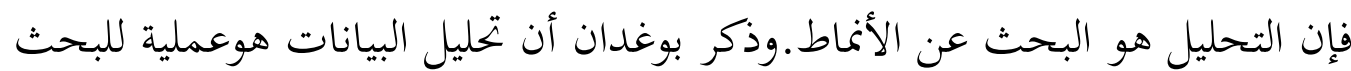
وبحميع البيانات بشكل منتظم من المقابلات والملاحظات الميدانية وغيرها من المواد،

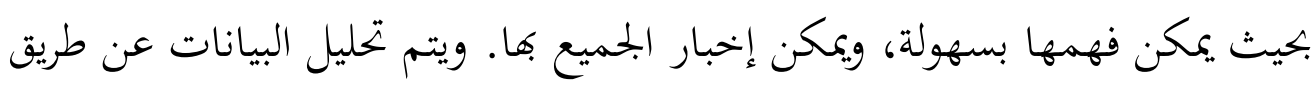
تنظيم البيانات، ووصفها إلى وحدات، وتوليف رها، وترتيبها في أنماط، واختيار أي منها

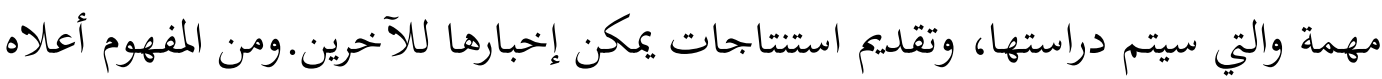

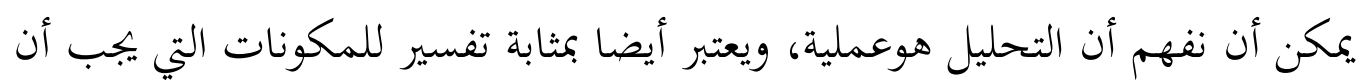
تكون موجودة في تحليل البيانات. لذا، فإن المقصود بالتحليل هنا هومعرفة المشكلة التي سيتم دراستها في الدراسة.' 1. . . هناك عدة خطوات يمكن للمدرس استخدامها عند تدريس مهارات التحدث، بما في ذلك: أ) للمتعلمين المبتدئين. ا ـ يبدأ المعلم في ممارسة التحدث بإعطاء أسئلة يجب الإجابة عليها من قبل الطلاب.

r. في الوقت نفسه، يُطلب من الطلاب تعلم نطق الكلمات وترتيب الجمل والتعبير

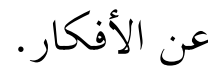

r. يقوم المعلم بفرز الأسئلة التي يجيب عليها الطلاب بحيث يشكلون موضوعًا مثاليًا. 
ع. يطلب المعلم من الطلاب الإجابة عن تمارين شفاهية أوحفظ المحادثات أوالإجابة على الأسئلة المتعلقة بمحتوى النص الذي قرأه الطلاب.

$$
\begin{aligned}
& \text { ب) للمتعلمين المتقدمين (المتوسطة) } \\
& \text { ا • تعلم التحدث عن طريق لعب الأدوار } \\
& \text { r بمناقشة الموضوع }
\end{aligned}
$$

r · بهكي قصص عن الأحداث التي يتعرض لها الطلاب

ع •يهكي عن المعلومات التي تم سماعها من التلفزيون أوالراديوأوغيرها.

ج). للمتعلمين المتقدمين (المستوى الأعلى)

ا • يختار المعلم موضوعًا لممارسة الكالام

r • يجب أن يكون الموضوع المختار مثيرً للاهتمام ومتعلقًا بحياة الطلاب

$$
\text { ب. بيجب أن يكون موضوع واضح ومحدود. }
$$

ع ·دعوة الطلاب لاختيار موضوعين أوأكثر حتى يصبح الطلاب في هاية المطاف

حراً في اختيار المظهر الذي تتم مناقشته حول ما يعرفونه.

بعض التعليمات العامة المتعلقة بتعلم الكالام، وهي كما يلي:

$$
\begin{aligned}
& \text { ا •تعلم الكلام الذي يمارس الكالام } \\
& \text { ץ.يجب على الطلاب التعبير عن بتاربهم }
\end{aligned}
$$

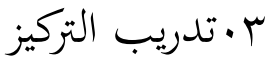

$$
\begin{aligned}
& \text { ع · لا تنقطع المحادثة وغالبًا ما تبررها } \\
& \text { 0 - تدريجيا }
\end{aligned}
$$

ج ·معنى الموضوع، سيكون الطلاب أكثر تحمسًا للتحدث إذاكان الموضوع متعلقًا بالأشياء الحقيقية في حياكهمَّ

' بصرى مصطفى, أبدل حميد, Metode Strategi Pembelajaran Bahasa Arab, 
وفي المرحلة الأولية، يمكن القول إن تدريب المحادثة مشابه لممارسة الاستماع. كما قيل من قبل، في ممارسة الاستماع هناك مراحل الاستماع والتقليد. تمرين الاستماع والتقليد هذا هومزيج من التدريب الأساسي لمهارات الاستماع ومهارات التحدث. ولكن يجب إدراك أن الهدف النهائي للاثنين مختلف، فالهدف النهائي لممارسة

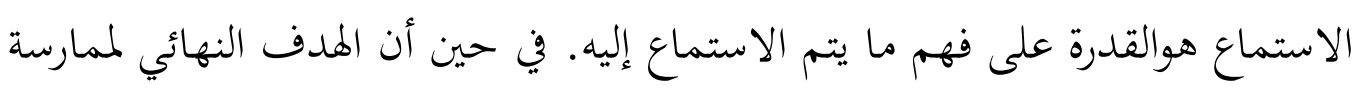

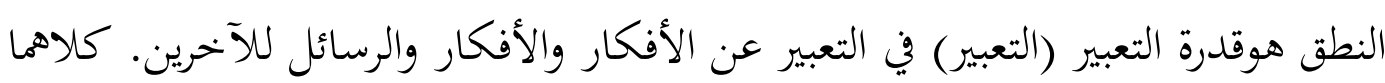
شروط مطلقة للاتصال شفهي فعال بالمثل. تشمل الاستراتيجيات التي يمكن استخدامها في تعلم مهارات التحدث: استراتيجية مباشرة. تحدف هذه الاستراتيجية إلى تدريب الطلاب على معرفة ما هومكتوب باللغتين

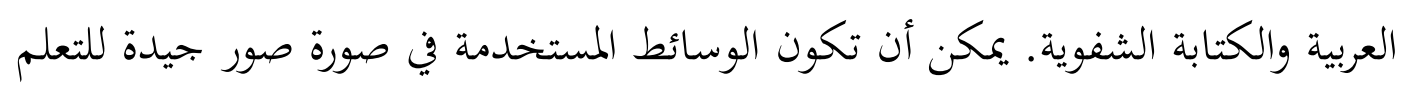
أم لا. استراتيجية بانوراما عادةً ما تستخدم هذه الاستراتيجية بهدف فهم محتويات القراءة ككل عن طريق

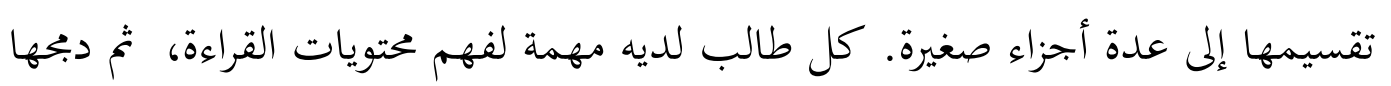

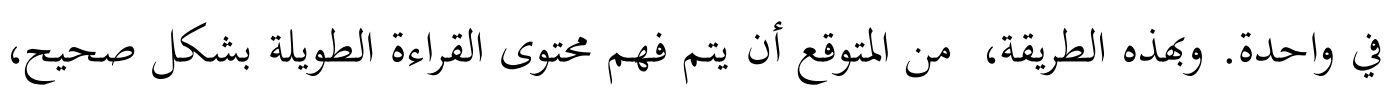
بالإضافة إلى أن عملية الفهم ستكون أعمق لأها تتكرر عدة مرات. استراتيجية صغيرة

غالبًا ما يشار إلى هذه الإستراتيجية باسم العرض التقديمي للمجموعة الصغيرة،

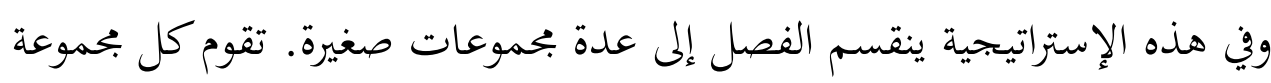

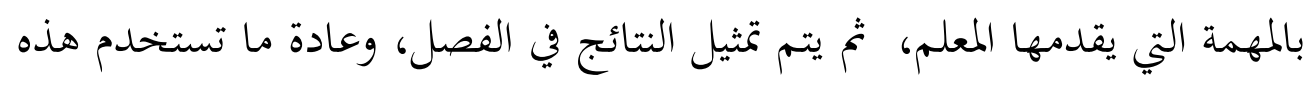
الاستراتيجية لزيادة تنشيط الطلاب، بحيث سيختبر كل طالب بتربة التعلم نفسها. 
استراتيجية لعرض الصوروهذا ما يسمى استراتيجية الجلسة. يظهر استخدام هذه الإستراتيجية ضمن أشياء أخرى لتدريب قدرة الطلاب على تعلم كيفية فهم محتويات القراءة ومن ثخم التمكن من تصورها في شكل صور. من الصورة، من المتوقع أن يتمكن جميع الطلاب من حفظ محتويات القراءة بسهولة وأن تستمر ذكريات الطلاب حول محتويات القراءة لفترة أطول. فيما يلي بعض نماذج محارسة التحدث.لا يوجد تسلسل يشير إلى التدرج / مستوى الصعوبة، وإن لم يكن مطلقًا.

يعتمد قياس مهارات التحدث على إيصال الرسائل أومعنى المتحدثين للمستمعين. لأن معنى اللغة بحردة، تمح لقياسه عن طريق قياس الأعراض التي تصف المعنى من خلال أنواع الكالام. هذه الأعراض هي: 1) النطق، وكيف يقول الطلاب كلمة أوجملة، 2 2قاعد اللغة، وكيف يحافظ الطلاب على قواعد قواعد اللغة في التحدث، 3) المفردات، مقدار المفردات التي يملكها الطلاب ويستخدموها في التحدث، 4) الفهم، إلى أي مدى يفهم الطلاب التواصل اللغوي المستخدم. لقياس المكونات الخمسة، يمكن التحدث بالعديد من الاختبارات أدناه: ويعد قياس الكلام أصعب شيء مقارنة بقياس المهارات اللغوية الأخرى. العديد من العوامل هي أسباب صعوبة اختبار قدرات الطلاب على التحدث، بما في ذلك ؛ عادة ما تكون طبيعة التحدث نفسها غير محددة جيدًا ؛ كيف يتم التوازن لكل جانبمن جوانب القدرة على الكام، مثل ؛ المفردات، والكالام، والقواعد، والطلاقة، والتفاهم، و؛ كيفية قياس جوانب القدرة على التحدث في وقت واحد. و التحدث هوقدرة إنتاجية نشطة، لأنه عند التحدث، يُطلب من المتحدث مبادرة حقيقية في استخدام اللغة للتعبير عن نفسه لفظياً. كقدرة إنتاجية نشطة، تتطلب القدرة على التحدث المتكلم لإتقان العديد من جوانب وقواعد اللغة، وأهم

$$
\text { شيء هوالتركيز على عناصر المحتوى أوالمعنى. }
$$

ץ طاهيرن, psikologi تعليم اللغة العربية, (جاكرتا : PT Raja Grafindo Persada 2018) ص. 122-124 
يقوم المشارك في الاختبار ب إجراء جملة أوخطاب قصير يعبر عن الموقف

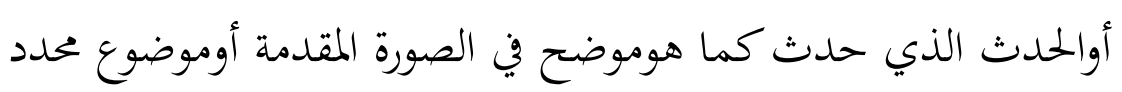
ب ) إعادة البيع

يقرأ المشارك في الاختبار خطابًا موجودًا في القراءة أويستمع إلى الخطاب في التسجيل، ثم يعيد التعبير عن محتوياته بلغته الخاصة عن طريق إعطاء الأولوية لألجزاء المهمة من القراءة أوالتسجيل. ج). تكلم بحرية

في شكل حرية التعبير، يتم إعطاء المشاركين في الاختبار عددًا من الموضوعات

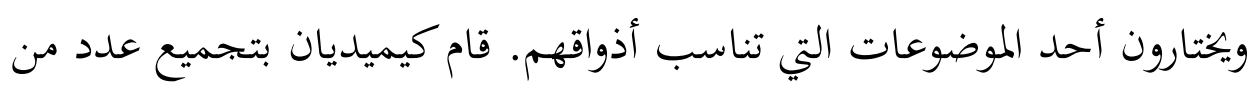
النقاط المتعلقة بالموضوع المختار واستخدم هذه النقاط الذهنية للتحدث لبضع دقائق ه). محادثة المحادثة هي شكل من أشكال الاختبار من خلال مطالبة اثنين أوأكثر من

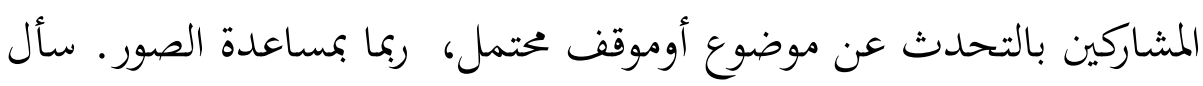
المشاركون في الاختبار بعضهم البعض أسئلة وأجوبة، وأعطوا المنشطات والردود

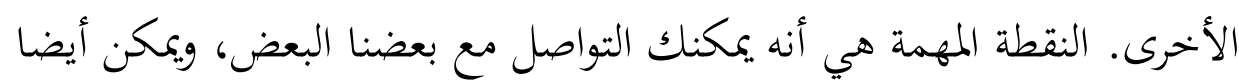
أن تكون في شكل مناقشة.

أ) مقابلة

المقابلة هي شكل من أشكال الاختبار من خلال طلب الإجابة أوالرد على المعاله

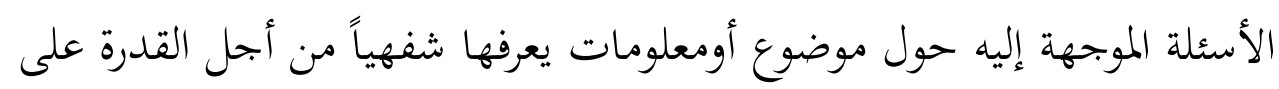

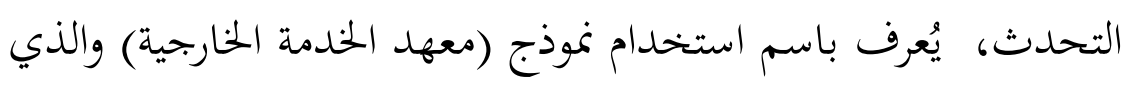

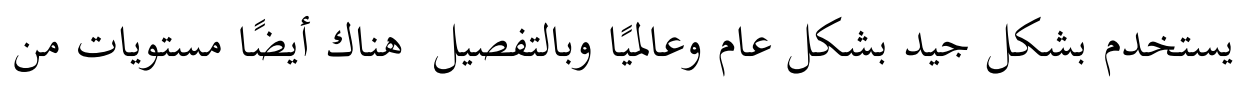
القدرة على التحدث وفقًا. 
نوع البحث وصفي نوعي. صرح أن "البحث الوصفي هو البحث الذي يهدف إلى تقديم وصف للحالات أوالأحداث. والمنهج المستخدم في هذه الدراسة هومنهج

نوعي، وهو البحث الذي أجري بمراقبة الظواهر المحيطة وتحليلها باستخدام المنطق العلمي (منطق التفكير الاستنتاجي الاستقرائي). استنادًا إلى طريقة البحث هذه التي يتم

تناولها بطريقة وصفية، وهي البحث الذي يهاول وصف الوضع الفعلي في الحقل وفقًا

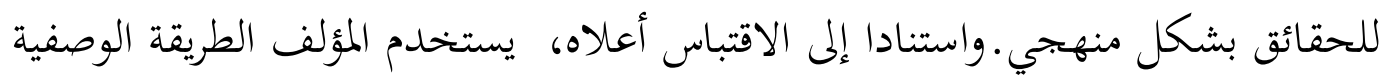

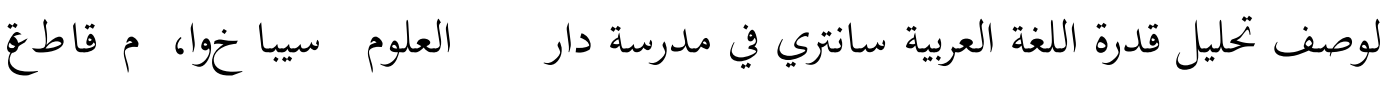
هالونجونان، مقاطعة بادانج لاواس الشمالية النتائج البحث

المهارة على محادثة باللغة العربية التلميذ مدرسة دار العلوم سيباخوا مركزية، هالونجونان مقاطعة بادنج لاوس الثمال ية. والمهارة على محادثة باللغة العربية التلميذ فصل السابع مدرسة دار العلوم سيباخوا مركزية هالونجونان مقاطعة بادنج لاوس

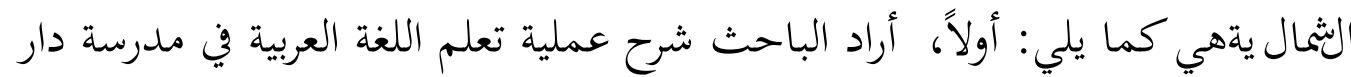

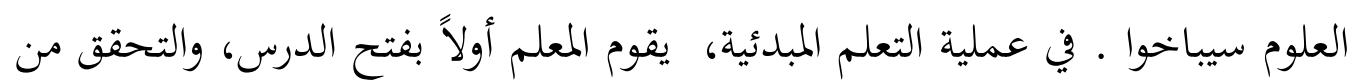

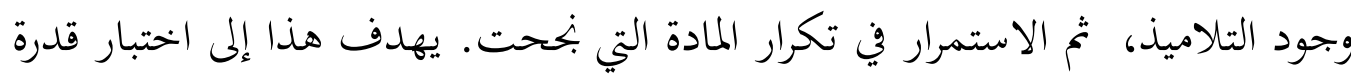
الطلاب على تذكر ما تم تدريسه من قبل وتم تعزيز ذلك بواسطة معلمي مادة اللغة العربية، و وعادة ما تكون المراحل الأولية

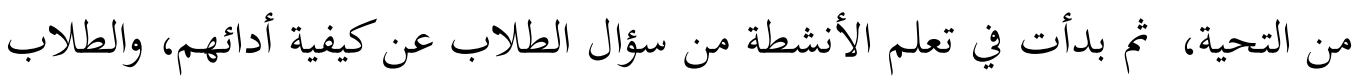

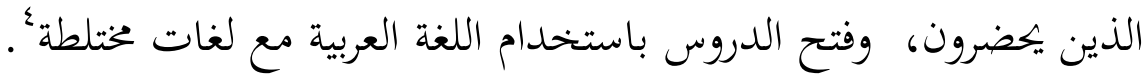

" أمرل حنفى, مدرس الغة العربية فصل السابعة السانوية دارالعلوم سيباخوا, مقابلة النفسى, في يوم ألخميس 15 
(8) Jurnal Thariqah IImiah Vol. 07 No. 02 Desember 2019

لذلك يستخدم مدرس اللغة العربية في عملية التعلم لغة مختلطة وهي باستخدام لغتين، تعد مهارة المعلم في فتح الدروس مهمة للغاية لأكها تحدد عملية استعداد المعلم في تقديم الموضوع كيف يفتح المعلم ويغيب عن حضور الطالب. المهارة على التحدث بل لغة ضرورية للغاية للطلاب في تعلم اللغة العربية. إن استخدام المفردات سوف يسهل ويساعد الطلاب على فهم اللغة شفهياً وخطياً. كما هومعروف أن القدرات التي يمتلكها الطلاب في استيعاب الدروس يجب أن يكون لها قدرات مختلفة. موجود أولئك الذين لديهم القدرة على استيعاب الدروس بسرعة، وموجود أولئك الذين لديهم قدرات ليست سريعة بما فيه الكفاية.

فيما يتعلق بالجهارة على التحدث باللغة العربية من حيث إتقان المفردات، يكون بعض الطلاب قادرين على التحدث بشكل صحيح وصحيح، والبعض الآخر أقل مهارة على التحدث بالعربية لأن كل طفل لديه قدرات مختلفة وسوف تظهر قدرة الطلاب على التحدث بالعربية عند إعطائهم الواجبات، وحفظ المفردات كل صباح وليلة في عنابر النوم، والمهندسة، وأيضًا تعيين الواجبات في فصول مثل إيما، إنشا، وغيرها من دروس اللغة العربية. الطلاب الذين يقال إهم قادرون على التحدث باللغة العربية هم الطلاب الذين يحفظون كل من المفردات الثفوية والمكتوبة، أوفي الممارسة العملية بطلاقة في محدسة، بينما بالنسبة للطلاب الذين لم يتمكنوا من التحدث هناك بالتأكيد الصعوبات التي يواجهها هؤلاء الطلاب. ما زالت قدرة الطلاب أنفسهم في مهارات اللغة العربية أقل تحفظًا. يمكن ملاحظة ذلك من خحلال عملية تعلم اللغة العربية، عندما أقوم ب إجراء اختبارات أوتمارين لاكتشاف مهاراتمم في اللغة العربية من خلال تقديم الأسئلة المناسبة لترجمة المفردات التي لا تزال في مستوى بسيط، ولكن معظم الطلاب لم يتمكنوا من ترجمة المفردات بشكل صحيح، وكذلك الكتابة إرجاع المفردات المعطاةْ .

• ملاحظات في مدرسة دار العلوم التناريخ يوي الأربعاء 14 أغسطس 2019 
بعد ذلك أجرى الباحثون مقابلات مع العديد من الطلاب في الفصل على النحوالتالي:

بناءً على نتائج المقابلات التي أجراها مع الطلاب، وهم محمد يوغي هارهاب، تمكنت من تعلم اللغة العربية، فابتداءً من مدرسة ابتيدائية، أحببت الدروس العربية

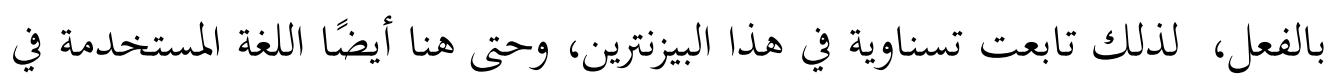

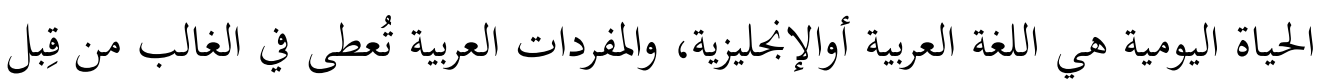
شقيق المنظمة أوتُعطى من قبل المعلم لحفظها ومهام أخرى، وأنا واثق جدًا من القيام بالمهمة.

وحالة أخرى مع عاجم سيريجر "أشعر بالسعادة أيضًا في متابعة الدروس العربية.

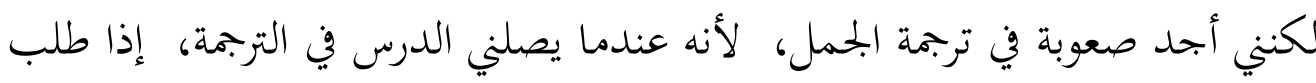

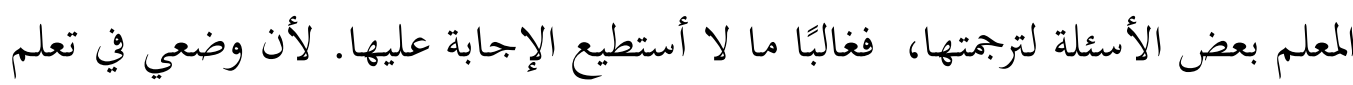

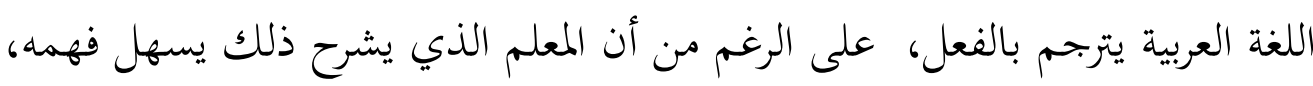

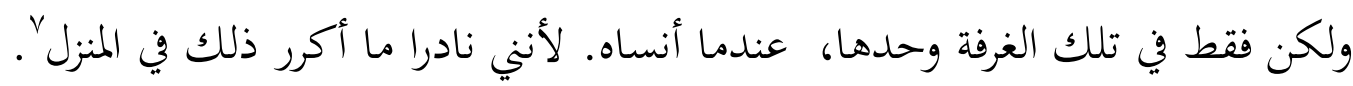

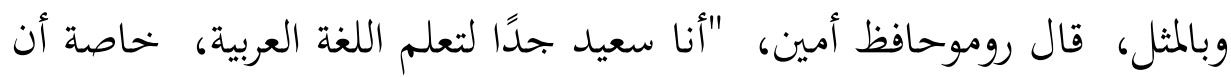
المعلم الذي يدرس في الغرفة جيد جدًا، إلى جانب المعلم الجيد الذي يدرس في التفسير

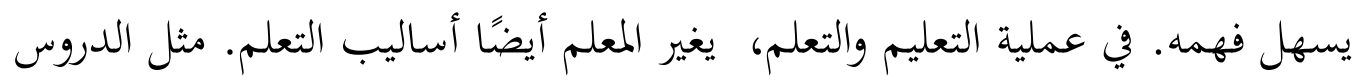

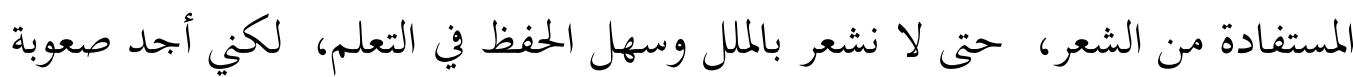

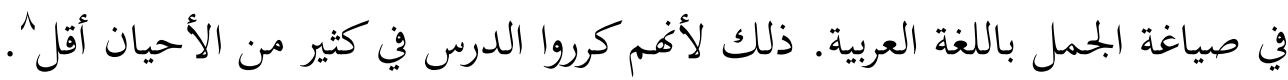

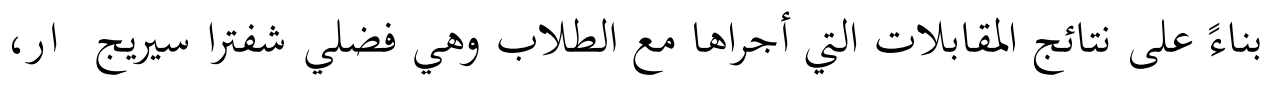

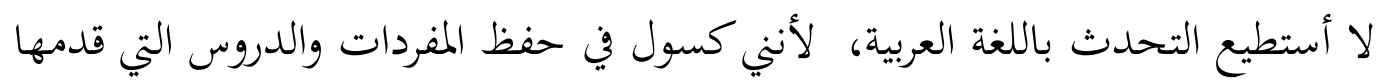

" محمد ياغى هراحف,هو الطلاب في مدرسة دار العلوم سيباخوا, مقابلة النفسى, في يوم الأربعاء أغسطس 2019

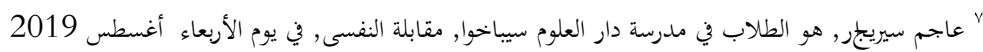

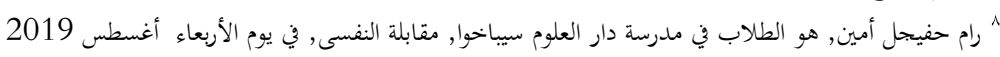


أستاذي غالبًا لا تستجيب على الإطالاق. ليس لأني أواجه وقتًا عصيبًا، لكني فقط كسبالى 9

بناءً على نتائج المقابالت التي أجراها مع الطلاب وتحديداً دخلت حبيبون الأول من المدرسة الداخلية، لم أحب اللغة العربية، لأني لم أحب تعلم اللغة العربية ولم أفهم الدروس التي قدمها المعلم '1 .

بناءً على نتائج المقابلات مع الطابل عبد العزيز هاسيبوان " في بداية درس النحوا، لم يعجبني هذا الدرس، على الرغم من أن طريقة شرح المادة كانت جيدة ويمكن فهمها بسهولة من قبل أصدقائي، وعندما درست كنت نائمًا، خاصةً إذا كان المعلم قد شرح الدرس، لذلك أنا لم أحصل على درجات جيدة' .' بناءً على نتائج المقابلة التي كشف عنها فوجي أعمل هاسبوان "أنا حقًا أحب اللغة العربية، لأنني أحب دروس اللغة العربية وأتفهم أيضًا الدروس التي قدمها، ودرجاتي جيدة دائمًا في تعلم المعلم 'ب . يتم دعم هذا أيضًا استنادًا إلى نتائج الملا حظة التي أبداها الطلاب في طلاب الفصل السابع الذين لا يزالون أقل مهارة، نظرًا لأن ردودهم على الدروس لا تزال تفتقر إلى التركيز، ويمكن ملاحظة ذلك عندما تتم عملية تعلم اللغة العربية في ساعات محددة. ينظر الباحثون إلى متى يسأل المعلم الطلاب عند دراسة اللغة العربية. في ذلك الوقت، أجاب البعض منهم فقط بشكل صحيح، على الرغم من أن الدرس المعني قد تم تقديمه

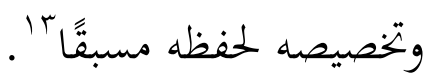

ن المقابلات والملاحظات أعلاه، يمكن ملاحظة أن الم هارة عللالتحدث باللغة العربية في مدرسة دار العلوم سيباخوا لا تزال أقل لمهارة، بناءً على المقابلات

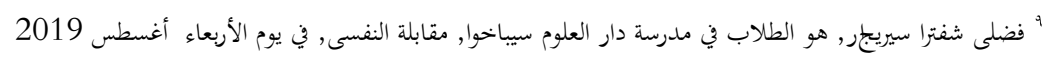

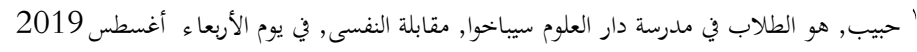

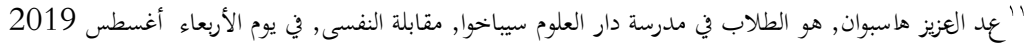

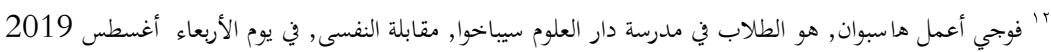

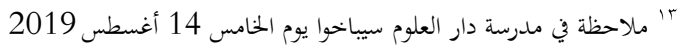


والملاحظات التي أجراها الباحثون ُ .وبيئة تعلم اللغة العربية في مدرسة دار العلوم

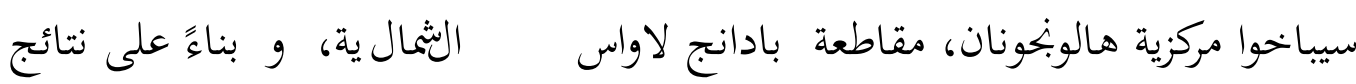

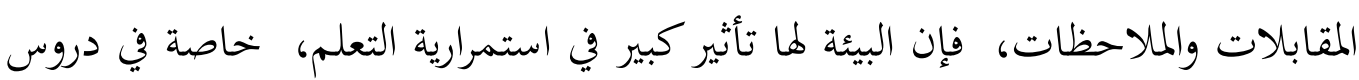
اللغة العربية. بيئة التعلم في مدرسة دار العلوم سيباخوا مركزية هالونجنان مقاطعة بادنج

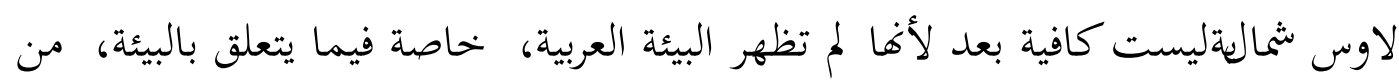

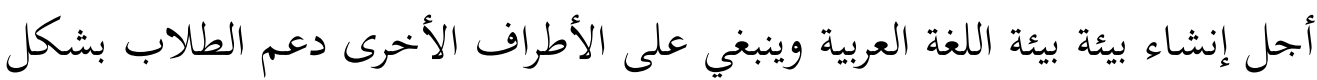

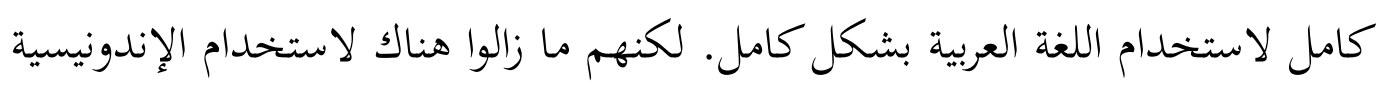
على الرغم من أفم يفهمون اللغة العربية بالفعل. ويستطيع جميع الطلاب تقريبًا قراءة

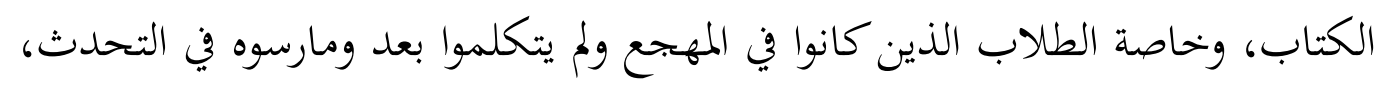

$$
\text { وما زال هناك بعض الذين يواجهون صعوبة' . }
$$

لإنشاء بيئة تعليمية فعالة، يجب أن يتم ممارستها دائمًا في بيئات رسمية وغير

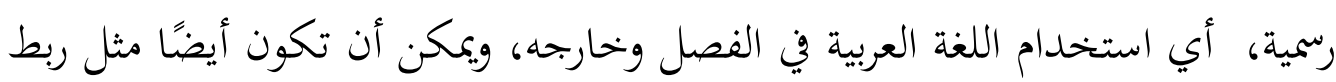

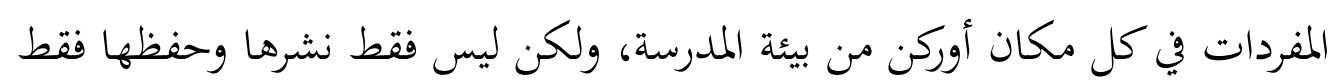
ويجب أن تطبق في الحياة اليومية.

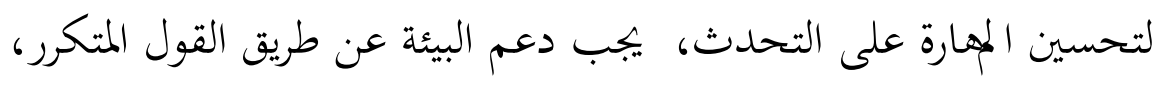

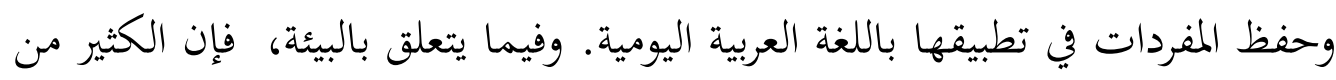

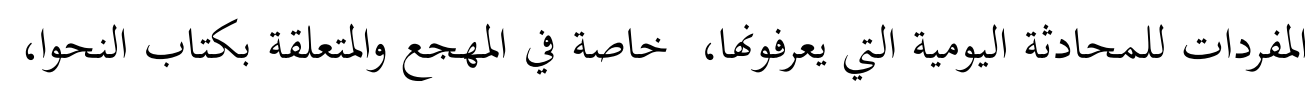

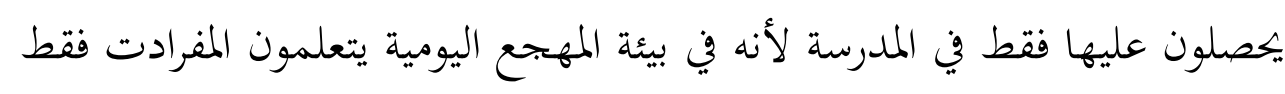
ومحادثة.

عوامل الصعوبات التي يواجهها التلميذ في اللغة العربية في مدرسة دار العلوم سيباخوامركزية هالوبجنان مقاطعة بادنج لاوس الثمال ية يوني

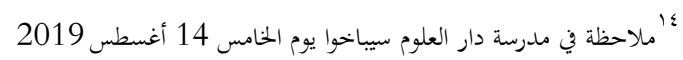

$$
\begin{aligned}
& \text { • ملاحظة في مدرسة دار العلوم سيبانوا يوم الخامس } 14 \text { أغسطس } 14 \text { ألغانس } 2019
\end{aligned}
$$


بناءً على نتائج المقابلات التي أجراها مع معلمي اللغة العربية في الصف الثامن في دار العلوم سيباخوامركزية هالوبجونان، مقاطعة بادانج لاواس الشمالية، هناك العديد من الصعوبات التي يواجهها المعلمون والطلاب والبنية التحتية والبيئة المدرسية. أ. أ. صعوبات المعلم

في تعلم اللغة العربية، واجهت نقصًا في الطلاقة لدى الطلاب الذين يحفظون المفردات مما يجعل من الصعب فهم الدومير باستخدام اللغة العربية الصحيحة والصحيحة.

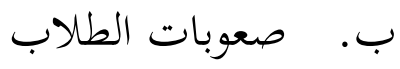

( ) قلة الطلاقة والطلاقة في نطق اللغة العربية بشكل صحيح. r) يشعر الطلاب بحفظ المفردات الصعبة كسولة للغاية ليقولها. ب) عدم تعلم النحوا وصرف مما يجعل من الصعب التمييز بين فعل يصبح عدم حفظ الطلاب في التعلم أحد الأجزاء التي يجب مراعاتا في بحال الدراسة، لأن حفظ الطلاب سيؤثر على عملية التعلم. لأن الحفظ في التعلم غالبًا ما يصبح أمرًا صعبًا على الطلاب لأنه ليس كل الطلاب لديهم نفس معدل الذكاء في التعلم. يمكن أن يأتي سبب الصعوبات من الطلاب أنفسهم الذين يعتقدون أن تعلم اللغة العربية أمر صعب وليس متعًا ويمكن أن يأتي أيضًا من بيئة الطلاب أنفسهم. مقابلة مع أصريل أري هارهاف "عدم إتقان النحوا، وشوروف وممارسة التحدث باللغة العربية، ما أدى إلى قلة الطلاقة في اللغة العربية. وفقًا لعبد العزيز حسيبوان، "غالبًا ما أجد صعوبة في تعلم اللغة العربية أثناء الدراسة، لأنه عندما يشرح المعلم اللغة العربية. أجد دائمًا صعوبة في تعلم اللغة العربية وأنا كسول جدًا في قول ذلكَ'ال. المقابلة التالية مع الأب حافظ أمين "لم أحفظ المفردات التي قدمها المعلم، وقد جعلني ثقتي خائفًا من أن أكون قادرًا على التمييز بين ماضي، مودريك، عمار. "17 مقابلة أصريل أري هار هاف, في مدرسة دار العلوم سيباخوا, في يوم الأربعاء أغسطس 2019 
من بعض المقابلات والملاحظات حول الصعوبات التي يواجهها الطلاب أعلاه والتي تجعل الطلاب أقل دعمًا في المج هارة على التحدث باللغة العربية ولكن إذا تمكن

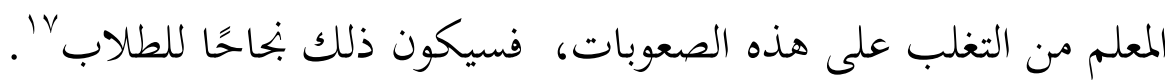
ج. صعوبات البنية التحتية

بالإضافة إلى المعلم، فإن عامل الطالب والمرافق والبنية التحتية مهمة أيضًا في العملية السلسة للتعلم والتدريس، لأن المرافق هي مكان لعملية التعلم. تعتبر الوسائل التعليمية أوأدوات التعلم من العوامل الداعمة والداعمة للغاية. د. البيئة المسكن

كما أن الاهتمام بالتعلم والبنية التحتية البيئية أمر داعم حتى يتسنى لمما التحدث باللغة العربية، إذا لم يتكلم الطلاب اللغة العربية بتجويد واضح، فلن تتحقق الجهارة على التحدث. بسبب حقيقة أن البيئة المدرسية تستخدم جزئيًا اللغات الإقليمية في الحياة اليومية، على الرغم من أها مطلوبة لاستخدام اللغة العربية، لأن البيئة للطلاب مؤثرة جدًا في الجهارة على التحدث باللغة العربية`' . من بعض المقابلات والمالاحظات حول الصعوبات التي يواجهها الطلاب أعلاه والتي تجعل الطلاب أقل دعمًا في المُ هارة على التحدث باللغة العربية ولكن إذا تمكن المعلم من التغلب على هذه الصعوبات، فسيكون ذلك بجاحًا للطلاب. ج. تحليل نتائج البحث

المهارة على الحيدثبا اللغة ض ضرورية للغاية للطلاب في تعلم اللغة العربية. إن استخدام المفردات سوف يسهل ويساعد الطلاب على فهم اللغة شفهياً وخطياً. كما هومعروف أن المهارات التي يمتلكها الطلاب في استيعاب الدروس يجب أن يكون لها مهارات مختلفة. موجود أولئك الذين لديهم القدرة على استيعاب الدروس بسرعة، وموجود أولئك الذين لديهم مهارات ليست سريعة بما فيه الكفاية.

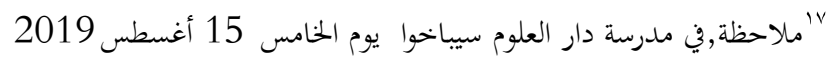

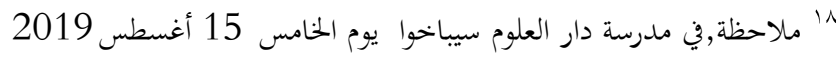


لتحسين المهارة على التحدث، يجب دعم البيئة عن طريق القول المتكرر،

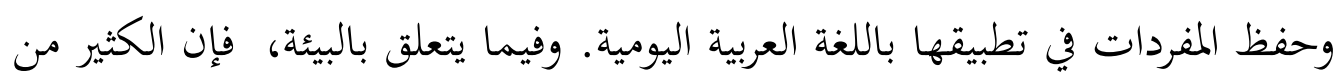

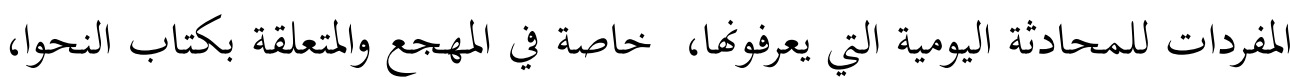
يجصلون عليها فقط في المدرسة لأنه في بيئة المهجع اليومية يتعلمون المفرادت فقط ئرئ ومحادثة.

يصبح عدم حفظ الطلاب في التعلم أحد الأجزاء التي يجب مراعاتا في بحال

الدراسة، لأن حفظ الطلاب سيؤثر على عملية التعلم. لأن الحفظ في التعلم غالبًا ما يصبح أمرًا صعبًا على الطلاب لأنه ليس كل الطلاب لديهم نفس معدل على الذكاء في التعلم.

يمكن أن يأتي سبب الصعوبات من الطلاب الذين كقومون أن تعلم اللغة العربية

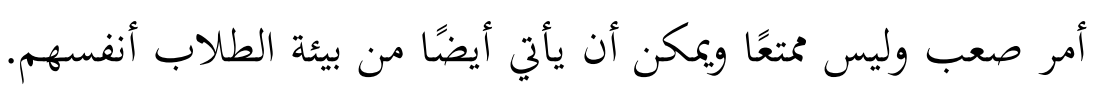

الخلاصة

بناءً على نتائج البحث، يمكن للبحث استخلاص النتائج كما يلي:

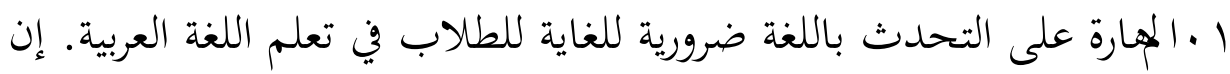

استخدام المفردات سوف يسهل ويساعد الطلاب على فهم اللغة شف وياً وخطياً.

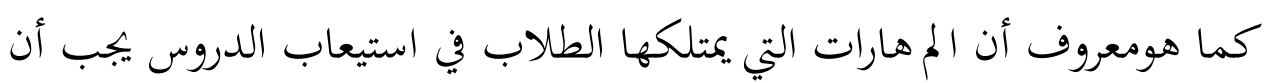

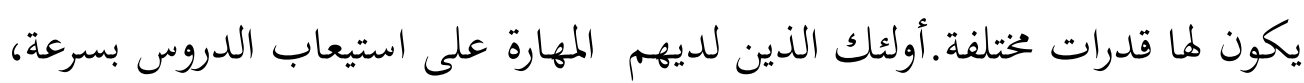
وبعض الذين لديهم قدرات ليست سريعة بما فيه الكفاية.

r.يجب ممارسة حالة البيئة التعليمية الفعالة دائمًا في بيئات رسمية وغير رسمية تستخدم اللغة العربية سواء في الفصل أوخارج الفصل، ويمكن أن تكون أيضًا مثل إرفاق كلمة

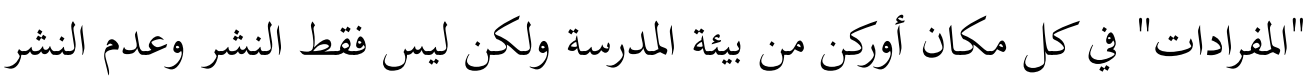
فتط يحفظ فتط ويجب أن تطبق في الحياة اليومية. 
سوغيونو, Metode Penelitian Pendekatan Kuantatif Kualitatif بندونغ: الفابت, $(2010$

UIN )Metode Strategi Pembelajaran Bahasa Arab, بصرى مصطفى, أبدل حميد (2012MALIKI PRESS

طاهيرن, psikologi تعليم اللغة العربية, (جاكرتا : , PT Raja Grafindo Persada 2018) أمرل حنفى, مدرس الغة العربية فصل السابعة السانوية دارالعلوم سيباخوا, مقابلة النفسى, في يوم ألخميس 15 أغسطس 2019 ملاحظات في مدرسة دارالعلوم التاريخ يوم الأربعاء 14 أغسطس 2019 